Short Communication

\title{
Antifungal Activity of the Essential Oils from Ocimum gratissimum L. Grown in Togo
}

\author{
Koffi Koba* ${ }^{1}$, Panopèndou Wiyao Poutouli ${ }^{2}$, Christine Raynaud ${ }^{3}$, Komla Sanda $^{1}$ \\ ${ }^{1}$ Unité de Recherche sur les Agroressources et la Santé Environnementale, Ecole Supérieure \\ d'Agronomie, Université de Lomé, BP. 1515, Lomé Togo \\ ${ }^{2}$ Département de Biologie Animale et de zoologie, Faculté des Sciences, Université de Lomé, B.P. \\ 1515 Lomé Togo \\ ${ }^{3}$ Laboratoire de Chimie Agro-Industrielle, UMR 1010, INRA/INP-ENSIACET, 118, route de \\ Narbonne, 31077 Toulouse cedex, France
}

Received 11 September 2008, accepted in final revised form 29 November 2008

\begin{abstract}
The aerial parts of Ocimum gratissimum L. (Lamiaceae) harvested in Togo was steamdistilled and investigated for essential oil composition (GC and GC/MS) and in vitro antifungal activities. Thymol (31.79\%), p-cymene (15.57\%) and $\gamma$-terpinene $(12.34 \%)$ and were the major components of the oil. Other notable components identified in this oil were myrcene $(6.94 \%)$ and $\alpha$-thujene $(6.11 \%)$. The in vitro antifungal activity was recorded with the minimum inhibitory concentrations (MICs) ranging from 80 to $150 \mu 1.1^{-1}, 150$ to 500 $\mu 1.1^{-1}$ and from 100 to $150 \mu 1.1^{-1}$ respectively on dermatophytes, imperfect filamentous fungi and pathogenic yeasts. Likewise, on tested fungi the minimum fungicidal concentration (MFC) varied from $300 \mu 1.1^{-1}$ to $500 \mu 1.1^{-1}, 500$ to $700 \mu 1.1^{-1}$ and from 250 to $300 \mu 1.1^{-1}$, respectively on dermatophytes, imperfect filamentous fungi and pathogenic yeasts.
\end{abstract}

Keywords: O.gratissimum, Antifungal, Essential oil; Thymol.

(C) 2009 JSR Publications. ISSN: 2070-0237 (Print); 2070-0245 (Online). All rights reserved.

DOI: $10.3329 /$ jsr.vlil.1131

\section{Introduction}

Tree basil (Ocimum gratissimum L., (Lamiaceae) is a well known species and commonly used in folk medicine in Africa [1, 2]. The genus Ocimum collectively known as basil, includes around 30 plant species from tropical and subtropical areas [3]. Ocimum are widely cultivated and extensively used for food, perfumery, cosmetics, pesticides, medicine, and traditional rituals because of their natural aroma and flavour and other properties [4, 5]. O. gratissimum is commonly used in folk medicine to treat different diseases like upper respiratory tract infections, diarrhoea, headaches, ophthalmic, skin

\footnotetext{
* Corresponding author: danielkkoba@yahoo.fr
} 
diseases, pneumonia and also a treatment of cough, fever, and conjunctivitis [6, 7]. Local populations in West Africa use the fresh leaves as mouth antiseptic [8, 9]. O. gratissimum herb is also used both as anthelmintic, antiparasitic [10,11], antimalarial [11], and as condiment that impart an acceptable flavour [12]. An infusion can be used as a digestive remedy, being taken to settle a wide range of problems such colic and stomach pains and diarrhoea [1]. The plant is also used as a fumigant against pests [13, 14]. Previous studies showed that $O$. gratissimum essential oils chemotypes displayed antimicrobial activities [15-17].The chemical composition of $O$. gratissimum essential oils has been intensively investigated [18-20], indicating that the thymol chemotype is the most widely distributed. At the same time, only very little work has been done on the chemical composition and the antimicrobial activities of basil oils from plants growing in Togo with pcymene/thymol as their major components showing moderate antimicrobial activities [19, 21]. The present study reports the chemical composition and the in vitro evaluation of $O$. gratissimum essential oil along with its fungistatic and fungicidal activities against seventeen fungal strains.

\section{Material and Methods}

\subsection{Plant material and isolation of volatile oils}

Leaves and inflorescences of $O$. gratissimum L. used in this work were harvested from plants at full flowering stage from the experimental field of the Unite de Recherche sur les Agroressources et la Santé Environnementale at the Université de Lomé in October 2007. Plant specimen was identified by Pr. Akpagana, Departement de Botanique, Faculté des Sciences at the Université de Lomé (Togo), where Voucher specimen was deposited in the Herbarium under reference $250 \mathrm{~K}$. A sample $(50 \mathrm{~g})$ of air-dried plant material was extracted by the hydro-distillation technique for 2 hours in a modified Clevenger-type glass apparatus [22]. The extracted crude essential oil was stored in hermetically sealed dark glass flask with rubber lids, covered with aluminium foil to protect the content from light and kept under refrigeration at $4{ }^{\circ} \mathrm{C}$ until use without any prior purification.

\subsection{Essential oil analyses}

\subsubsection{Gas chromatography analysis}

Gas chromatographic analysis was carried out on a Varian 3300 type gas chromatograph equipped with FID detector. An apolar capillary column DB-5 (30 m x 0.25 mm i.d.; film thickness $0.25 \mu \mathrm{m}$ ) and on a polar column Supelcowax 10 with the same characteristics as above mentioned were used. DB-5 column operating conditions were as follows: from $50^{\circ} \mathrm{C}(5 \mathrm{~min}), 50^{\circ} \mathrm{C}$ to $250^{\circ} \mathrm{C}$ at the rate of $2^{\circ} \mathrm{C} / \mathrm{min}$ and Supelcowax 10 from $50^{\circ} \mathrm{C}(5$ $\min ), 50^{\circ} \mathrm{C}$ to $200^{\circ} \mathrm{C}$ at $2{ }^{\circ} \mathrm{C} / \mathrm{min}$. The injector and detector temperatures were $250{ }^{\circ} \mathrm{C}$ and $300^{\circ} \mathrm{C}$, respectively. The carrier gas was helium at a flow rate of $1.50 \mathrm{ml} / \mathrm{min}$. Samples $(0.2 \mu \mathrm{l})$ of non diluted essential oil were injected manually. 


\subsubsection{Chromatography-Mass spectrometry analysis}

The GC/MS analysis was carried out on a Hewlett Packard 5890 SERIES II chromatograph, coupled with a mass spectrometer of the Hewlett Packard 5971 SERIES type operating in the EI mode at $70 \mathrm{eV}$. The capillary column type was DB5-MS (30 m x $0.25 \mathrm{~mm}$ i.d.; film thickness $0.25 \mu \mathrm{m}$ ). The amount of sample injected and GC/MS parameters were the same as above.

\subsubsection{Identification of components}

The components of oil samples was identified by their retention time, retention indices relative to $\mathrm{C}_{5}-\mathrm{C}_{18} \mathrm{n}$-alkanes, computer matching with with Willet 275.L library and as well as by comparison of their mass spectra with the authentic samples or with data already available in the literature $[23,24]$. The percentage of composition of the identified compounds was computed from the GC peak area without any correction factor and was calculated relatively.

\subsection{In vitro antifungal testing}

Fungal strains used are listed in Table 2. The strains were supplied by the Institut Pasteur de Paris (IP), Hôpital Saint Jacques de Besançon (France) (B) and Laboratoire de Bactériologie-Parasitologie du Centre Hospitalier Universitaire de Pointe à Pitre/Abymes, Guadeloupe (G). The fungi were cultivated on a Sabouraud Agar Medium in which was added chloramphenicol 1\%, all purchased from BioMerieux Co. (Paris, France). Pure thymol, $\gamma$-terpinene, and p-cymene commercial standards were also purchased from BioMerieux Co. (Paris, France).The antimicrobial activities of the essential oil were assessed according to Agar dilution method [25]. The tested essential oil and its pure major components from commercial origin were diluted in a minimal quantity of ethanol $95 \% 1 / 10 \mathrm{v} / \mathrm{v}$ to which was added an aqueous solution of Tween 80 (final concentration of $1 \% \mathrm{v} / \mathrm{v}$ ) in order to obtain a homogeneous mixture. The later was incorporated as appropriate to the microbiological culture medium under solidification to obtain final concentrations of the active ingredient that ranged from 10 to $500 \mu 1.1^{-1}$. The mixture was then poured into $3 \mathrm{~cm}$ diameter Petri dishes.

After solidification fungal strains were respectively seeded as described below:

(i) dermatophytes were seeded with a disc of approximately $2 \mathrm{~mm}$, from a mycelia carpet of preculture, laid in the middle area of a new Petri dishes, upper side against the new culture medium;

(ii) $1 \mathrm{ml}$ of a suspension of $10^{5}$ conidia per millilitre of Aspergillus fumigatus or $10^{5}$ blastospores per millilitre of yeast was poured on the surface of the culture medium. Incubation time and temperatures depended on the fungal strains: 24 hours at $37^{\circ} \mathrm{C}$ for Candida albicans and Aspergillus, 48 hours at $37^{\circ} \mathrm{C}$ for Cryptococcus, 14 days at $24^{\circ} \mathrm{C}$ for the dermatophytes and Scopulariopsis brevicaulis. 
The antifungal activities were evaluated by the determination of the minimum inhibitory concentration (MIC) and the minimum fungicidal concentration (MFC). The minimum inhibitory concentrations (MICs) were determined as the lowest concentration of the test active ingredient that resulted in a complete inhibition of visible growth of the microorganisms. The minimum fungicidal concentrations (MFCs) were determined as the lowest concentration of the test active ingredient which did not allow any visible growth of the microorganisms after subculture. All tests were carried out in triplicate.

\section{Results and Discussion}

\subsection{Chemical analysis}

The steam distillation of the leaves and inflorescences of $O$. gratissimum produced a lightYellow essential oil in a $1.8 \%$ yield based on dried material. It gave off a flavour

\begin{tabular}{|c|c|c|}
\hline Compounds & RI* & Peak Area $[\%]^{\#}$ \\
\hline Monoterpene hydrocarbons & & 56.21 \\
\hline$\alpha$-thujene & 930 & 6.11 \\
\hline$\alpha$-pinene & 940 & 1.84 \\
\hline sabinene & 976 & 0.56 \\
\hline$\beta$-pinene & 990 & 0.74 \\
\hline mycene & 992 & 6.94 \\
\hline$\alpha$-phellandrene & 1010 & 0.35 \\
\hline$\alpha$-terpinene & 1023 & 4.02 \\
\hline$\beta$-phellandrene & 1027 & 0.28 \\
\hline para-cymene & 1030 & 15.57 \\
\hline limonene & 1036 & 0.57 \\
\hline Ocimene $(Z)$ - $\beta$ & 1037 & 0.43 \\
\hline Ocimene (E)- $\beta$ & 1058 & 1.75 \\
\hline$\gamma$-terpinene & 1078 & 12.34 \\
\hline p-cymenene & 1091 & 2.11 \\
\hline terpinolene & 1095 & 2.60 \\
\hline Oxygenated monoterpenes & & 37.85 \\
\hline thymol & 1290 & 31.79 \\
\hline carvacrol & 1299 & 1.44 \\
\hline cis hydrate de sabinene & 1076 & 0.76 \\
\hline tr-hydrate de sabinene & 1109 & 2.26 \\
\hline linalool & 1113 & 0,47 \\
\hline Terpineol-4 & 1179 & 1.13 \\
\hline Sesquiterpene hydrocarbons & & 3.80 \\
\hline$\alpha$-copaene & 1377 & 0.85 \\
\hline$\beta$-elemene & 1387 & 0.45 \\
\hline$\beta$-caryophyllene & 1420 & 1.71 \\
\hline$\alpha$-humulene & 1454 & 0.30 \\
\hline$\alpha$-selinene & 1498 & 0.49 \\
\hline Total identified & & 98.06 \\
\hline
\end{tabular}


reminiscent close to that of thymol. The oil constituents and its relative percentage are listed in Table 1.

Twenty six components were identified in the essential oil of $O$. gratissimum representing $98.06 \%$ out of the total detected compounds. Thymol (31.79\%) p-cymene $(15.57 \%)$ and $\gamma$-terpinene $(12.34 \%)$ and were the major components. Other notable components identified in this oil were myrcene $(6.94 \%)$ and $\alpha$-thujene $(6.11 \%)$. This oil consisted of sixteen monoterpene hydrocarbons $(57.06 \%)$, six oxygenated monoterpenes $(37.85 \%)$ and four sesquiterne hydrocarbons (2.95).

This chemical composition was closer to two previously described samples of $O$. gratissimum from Rwanda by Ntezurubanza et al. [26] with 35.42 to $47.85 \%$ in thymol amount and samples of $O$. gratissimum oils collected in various localities in Benin described by Yayi et al. [20] with thymol amount varied from 25.9 to $65.4 \%$.

\section{2. Antifungal activities}

The experimental data in Table 2 show that all fungal strains tested were sensitive to the essential oil of $O$. gratissimum but dermatophytes were particularly affected.

Table 2. Antifungal activity of $O$. gratissimum essential oil from Togo.

\begin{tabular}{|c|c|c|c|c|c|}
\hline \multirow{3}{*}{ Fungal strains } & \multicolumn{2}{|c|}{ Essential oil } & \multicolumn{3}{|c|}{ Major components } \\
\hline & MIC $(\mu \mathrm{L} / \mathrm{L})$ & \multirow[t]{2}{*}{ MFC $(\mu \mathrm{L} / \mathrm{L})$} & \multicolumn{3}{|c|}{ MIC $(\mu \mathrm{L} / \mathrm{L})$} \\
\hline & Ocimum gratissimum & & Thymol & $\gamma$-terpinene & p-cymene \\
\hline \multicolumn{6}{|l|}{ Dermatophytes } \\
\hline Trichophyton. mentagrophytes $(\mathrm{B})^{*}$ & 100 & 350 & 50 & $>500$ & $>500$ \\
\hline T. interdigitale $(\mathrm{B})$ & 80 & 300 & 100 & $>500$ & $>500$ \\
\hline T. interdigitale $(\mathrm{G})$ & 80 & 300 & 100 & $>500$ & $>500$ \\
\hline T. rubrum (B) & 80 & 300 & 50 & $>500$ & $>500$ \\
\hline T. erinaceum $(\mathrm{B})$ & 80 & 300 & 50 & $>500$ & $>500$ \\
\hline T. soudanense $(\mathrm{B})$ & 80 & 300 & 40 & $>500$ & $>500$ \\
\hline T. violaceum $(\mathrm{B})$ & 150 & 300 & 30 & $>500$ & $>500$ \\
\hline Microsporum canis (IP)* & 80 & 300 & 50 & $>500$ & $>500$ \\
\hline Microsporum canis $(\mathrm{G}){ }^{*}$ & 100 & 300 & 50 & $>500$ & $>500$ \\
\hline Microsporum gypseum (IP) & 100 & 300 & 50 & $>500$ & $>500$ \\
\hline Epidermophyton flocosum (B) & 150 & 300 & 50 & $>500$ & $>500$ \\
\hline \multicolumn{6}{|l|}{ Imperfect filamentous fungi } \\
\hline Aspergillus fumigatus (B) & 150 & 500 & 125 & $>500$ & $>500$ \\
\hline Scopulariopsis brevicaulis (B) & 200 & 500 & 75 & $>500$ & $>500$ \\
\hline Scytalidium dimidiatum & 500 & 700 & 150 & $>500$ & $>500$ \\
\hline \multicolumn{6}{|l|}{ Pathogenic yeasts } \\
\hline Candida albicans $(\mathrm{B})$ & 150 & 500 & 75 & $>500$ & $>500$ \\
\hline Cryptococcus neoformans (B) & 100 & 300 & 50 & $>500$ & $>500$ \\
\hline Malassezia pachydermatis (IP) & 150 & 300 & 50 & $>500$ & $>500$ \\
\hline
\end{tabular}

* Fungal strains origins.

(B) : Hôpital Saint Jacques de Besançon (France); IP : Institut Pasteur de Paris (France); G : Laboratoire de Bactériologie-Parasitologie du Centre Hospitalier Universitaire de Pointe à Pitre/Abymes, Guadeloupe. 
Hence, markedly low MICs $\left(80 \mu 1.1^{-1}\right)$ were recorded with $T$. interdigitale, T. rubrum, T. erinaceum, T. soudanense and Microsporum canis. The fungicidal activity of the test essential oil sample was quite identical on all dermatophytes (MFC: $300 \mu 1.1^{-1}$ ) except $T$. mentagrophytes var mentagrophytes (MFC: $350 \mu 1.1^{-1)}$. Along with dermatophytes, filamentous fungi were also sensitive to the test volatile oil; MICs were in the range of $150 \mu 1.1^{-1}$ to $500 \mu 1.1^{-1}$. Likewise, the essential oil sample appeared toxic to pathogenic yeast strains like Candida, Cryptococcus, Aspergillus, and Scopulariopsis with antifungal effect (MIC: from 100 to $150 \mu 1.1^{-1}$; MFC: from 250 to $300 \mu 1.1^{-1)}$. Also quite noticeable was the antifungal effect (MIC: $500 \mu 1.1^{-1}$; MFC: $700 \mu 1.1^{-1}$ ) of the test oil on strain of Scytalidium dimidiatum. The later, which often resist conventional antibiotics, is a very frequent human parasites in Caribbean and in Subsaharan Africa regions. The African Trichophyton soudanense, a parasite frequent in school environment [27] is interestingly also sensitive to the tested essential oil. It was also the case for Cryptococcus neoformans, a hazardous opportunist yeast, which is a resistant germ usually infecting humans affected by HIV/AIDS, which group of patients is known to be generally at high risk with regard to mycosis opportune affections.

The high antifungal activity of this chemotype of $O$. gratissimum essential oil on those pathogenic fungi like dermatophytes, filamentous fungi and yeasts confirmed the excellent fungal growth inhibition properties previously reported as a characteristic of essential oils rich in thymol and/or other phenol derivatives [28].

In this work it is obvious that the antifungal potential of $O$. gratissimum against tested fungi is a predictable consequence of its high content in thymol because it has been reported that the volatile oil of $O$. gratissimum contains mostly phenols, particularly thymol $[29,30]$ and that these are probably responsible for its reported antimicrobial properties. But commercial p-cymene and $\gamma$-terpinene tested as standards in this study were found non effective unlike pure thymol standard.

\section{Conclusion}

In this paper, the investigation of the percentage chemical of the essential oils of $O$. gratissimum confirmed the existence of previously discovered chemotypes containing respectively thymol as principal constituent this plant oil in Togo. The assessment of the antifungal properties of this chemotype on fungal strains responsible of various superficial mycosis is quite a typical applied research. The present study has shown that it is feasible to use $O$. gratissimum aerial part essential oil rich in phenolic derivatives as natural powerful antifungal ingredient.

\section{Acknowledgments}

The authors wish to thank Agence Universitaire de la Francophonie (AUF) and Service de Coopération et d'Action culturelle à Lomé (SCAC) for financial support. 


\section{References}

1. E. Adjanohoun, M. R. A Ahyi, L. Aké Assi, K. Akpagana, P. Chibon, A. El-Hadj, I. Eymen, E. Goutote, S. Ginko, K. K. Hodouto, P. Hougnon, A. Keita, Y. Kéoula, W. P. Klouga-Ocloo, I. Lo, K. Siamevi, K. K. Taffame, M. Garba, J. N. Gassita, and M. Gbeassor, Médecine traditionnelle et Pharmacopée: Contribution aux études ethnobotaniques et floristiques du Togo. ACCT, Paris (1986) p. 671.

2. L. Jirovetz, G. Buchbauer, and M. B. Ngassoum, Ernahrung. 22 (9), 395 (1998).

3. A. Paton, Kew Bull. 47, 403 (1992). doi:10.2307/4110571

4. U. P. Albuquerque, Dissertação (Mestrado em Biologia Vegetal) - Centro de Ciencias Biológicas, Universidade Federal de Pernambuco (1996).

5. H. Darrah, Econ. Bota. 28, 63 (1974).

6. M. .P. Corrêa, Dicionário das plantas Ũteis do Bresil. IBDF, Minstério da Agricultura, Rio de Janeiro (1932) p. 63.

7. F. D. Onajobi, J. Ethnolpharmacol. 18, 3 (1986).

8. R. Braga, Plantas do Nordeste, especialmente do Ceará Colecâo Mossoroense. Rio Grande do Norte, 1204, 23 (2001).

9. F. J. A. Matos, Plantas Medicinais, Guia de Seleção e Emprego de plantas usadas em Fitoterapia no Nordeste do Bresil. Imp. Univ. Fortleza (2000) p. 173.

10. L. M. Pessoa, S. M. Morais, and J. H. S. Luciano, Vet. Pathol. 109, 59 (2002).

11. P. U. Agomo, J. C. Idigo, B. M. Afolabi, Afr. J. Med. Med. Sci. 21(2), 39 (1992).

12. K. Koba Thèse de doctorat unique, Faculté des Sciences. Université de Lomé; Togo, $n^{\circ} .080(2003)$.

13. S. M. Keita, C. Vincent, J. Schmith, J. T. Arnason, and A. Belanger, J. Stored Prod. Res. 37 (4), 339 (2001). doi:10.1016/S0022-474X(00)00034-5

14. H. Kouninki, E. Haubruge, F. E. Noudjou, G. Lognac, F. Malaisse, M.B. Ngassoum, A. Goudoum, P. M. Mapongmetsem, L. S. Ngamo, and T. Hance, Commun. Agric. Appl. Biol. Sci. 70 (4), 787 (2005).

15. A. M. Janssen, J. J. Scheffer, L. Ntezurubenza, and S. A. Baerheim, J. Ethnopharmcol. 26 (1), 57 (1989).

16. J. A Lemos, X. S. Passos, O. F. Fernandes, J. R. Paula, P. H. Ferri, L. K. Souza, A. A. Lemos, and M. R. Silva, Mem. Inst. Oswaldo Cruz. 100 (1), 55 (2005).

17. M. R. Silva, J. G. J. Oliveira, O. F. Fernandes, X. S. Passos, C. R. Costa, L. K. Souza, J. A. Lemos, and J. R. Paula, Mycoses. 48 (3), 172 (2005). doi:10.1111/j.14390507.2005.01100.x

18. M. Ndounga and J. M. Ouamba, Fitoterapia. 18 (2), 190 (1997).

19. K. Sanda, K. Koba, P. Nambo, and A.Gaset, Flav Fragr J. 13, 226 (1998).

20. E. Yayi, M. Moudachirou, and J. C. Chalchat, J. Essent. Oil Res.13, 13 (2001).

21. K. Koumaglo, K. Dotse, K. Akpagana, F. X. Garneau, H. Gagnon, I. F. Jean, M. Moudachirou, I. Addae-Mensah, Riv. Ital. EPPOS. 7, 680 (1996).

22. A. A. Craveiro, F. J. Matos, and J. W. Alencar, J. Chem. Ed. 53, 652 (1976).

23. N. Kondjoyan and J. L. Berdagué, A compilation of relative retention indices for the analysis of aromatic compounds: Ed. Laboratoire Flaveur, INRA de Theix, France (1996).

24. R. P. Adams, Identification of essential oil components by gas chromatography/ quadrupole mass spectroscopy, Allured Publishing Corporation, Carol Stream, Ilinois. (2001) pp 9-24.

25. S. G. Griffin, J. L. Markham, and D. N. Leach, J. Essent. Oil Res. 12(2), 249 (2000). 
26. L. Ntezurubenza., J. J. C. Scheffer, and S. A. Baerheim, Planta Med. 53 (5), 421 (1987).

27. L. Ouaffak., A. Gati \& M. Lyagoubi, J. Mycol. Méd. 11 (4), 181 (2001).

28. J. P. Chaumont, D. Leger, Plant Med Phytother. 23, 124 (1989).

29. B. Oliver, Medicinal plants in Nigeria, Nigerian College of Arts, Science and Technology, Nigeria, (1960) p. 42.

30. M. Sainsbury, E. A. Sofowora, Phytochemistry 10, 3309 (1971). doi:10.1016/S00319422(00)97406-5 